\title{
Experimental Design For Single Degree Of Freedom Vibration System
}

\author{
S.Santhosh ${ }^{1}$, S. Periyasamy ${ }^{2}$ \\ ${ }^{1}$ P.G.Scholar, Department of Engineering Design, \\ Government college of Technology, Coimbatore-13, Tamilnadu - India. \\ ${ }^{2}$ Assistant Professor, Department of Mechanical Engineering, \\ Government college of Technology, Coimbatore-13, Tamilnadu - India. \\ Email: santhoshsivaklm@gmail.com ${ }^{1}$,speriyyasamy@gmail.com ${ }^{2}$
}

\begin{abstract}
Generally, any system which possess both mass and elasticity with the initial disturbance tend to vibrate. The repetition of such motion over a certain period of time is said to be mechanical vibrations. One of the simplest vibratory system is spring mass system, in which if the mass is allowed to travel along the elongation of spring direction is known as single degree of freedom system. The frequency of free vibration is the natural frequency of the system. In this project, how a single degree-free vibration spring mass system is designed and fabricated under cost effective manner. Initially the suitable spring and mass is been decided. The vibratory responses generated is measured using accelerometer. The mechanical displacement of spring can be measured manually and hence compared with sensor readings. The readings are been displayed using display unit. These readings are given to MATLAB software for obtaining vibratory responses. Finally theoretical and sensor readings are compared to obtain a effective spring mass system. Hence this system is then used to determine the tool vibration in conventional machines.
\end{abstract}

Index Terms- mechanical vibration; spring mass system; MATLAB.

\section{INTRODUCTION}

The theory of vibration deals with the study of oscillatory motions of bodies and the forces associated with them. In general, a vibratory system includes a means for storing potential energy ,a means for storing kinetic energy and a means by which energy is gradually lost. This system involves the transfer of its potential energy to kinetic energy and of kinetic energy to potential energy, alternately. If the system is damped, some energy is dissipated in each cycle of vibration and must be replaced by an external source if a state of steady vibration is to be maintained. The minimum number of independent coordinates required to specify the motion of a system at any instant is known as degree of freedom of system. In general, it is equal to number of independent displacements. This might vary from zero to infinity. In single degree of freedom system there is only one independent coordinate required to specify the motion. The response of a vibrating system generally depends on the initial conditions as well as the external excitations.

MATLAB is a high-performance language for technical computing. It helps us to find out the solution for the mathematical problems arise during experimentation process. Generally, a vibration testing machine is used for measuring the vibration parameters in different applications. Based on their functionality and accuracy their cost increases. In order to reduce the cost, there should be conciliation between functionality and accuracy.

Here a vibration measuring equipment with spring mass system is designed and fabricated in cost effective manner. This system measures the natural frequency of the spring corresponding to the suspended mass, which helps the students to know about the concept behind the vibration.

\section{RELATED WORK}

From the following literatures the necessary information related to this project work was referred. O.B.Abouelatta et al.,[1] forecasted the surface roughness related to machining parameters for turning operations . Hence derived a mathematical model for predicted roughness parameters based on cutting parameters and machine tool vibrations.an FFT analyzer is used to measure the tool vibrations and then compared with MATLAB software results. P.Edwin Sudhagar [2] evaluated the vibration characteristics of a laminated composite with ply drop-offs with tapered structure by means of finite element method which also includes deformation shear and effect of inertia during rotation .Julien Meaud [3] evaluated elastic wave propagation in 2D periodic lattices along with discontinuous pattern of nonlinear bistable springs and linear springs. From the experimental simulations lattices can be made as perfect replacement for phononic crystals with tunable directivity. Analysis is done for the above specified material with low frequency and also within directional bandgaps.

Hiyoshi et al., [4] determined the control of vibration for a flexible arm movement with feedback of expected reaction torque. The dynamical behavior of flexible link arm is described as a multiple mass spring model which is useful for the controller design and analysis. 
Wolfgang Reinelt [5] premeditated a two cart spring coupled robust controller. The input constraints are the benchmark collection for the robust control of a twomass spring system. Naveen Kuppuswamy [6] considered the relationship between development of ontogenetic and growth for motor control with the view on concentrated dimensionality. Thus, the effect of physical variation on the reduced dimensional control of a mass-spring-damper chain system. Zhi-Jia Zhang [8] proceeded the free vibration analysis for honeycomb structured sandwich beams. The honeycomb structures not only improves their natural frequency but also flexural rigidity of higher orders. This enhelps to eliminate stiffness anisotropy for the suppression of local vibrational modes. G.J.Liao et al., [9] developed the tunable stiffness and damping vibration isolator based on magnetorheological elastomers. The four MRE elements are used as tunable springs, whose stiffness can be controlled by varying the magnetic field. Thus, the rms values and maximum values of the velocity responses are decreased as compared with initial conditions.G A Yashavantha kumar et al.free vibration analysis of smart composite beam in which a smart beam consists of glass/epoxy composite as a main substrate and two PZT patches. These patches are glued above and below the main beam. By experimentation the natural frequencies and mode shapes are obtained for both with and without PZT patches of a beam

\section{MATERIALS AND METHODOLOGY}

For a spring mass system, the material of the spring should be decided based on its applications. Here we are considered spring alloy tempered stainless steel. The three springs are taken for vibration measurement. Masses of standard values are chosen for loading and unloading of spring. For the longer usage of springs, the springs should be tempered with stainless steel for higher corrosion resistance. Modulus of $\operatorname{rigidity}(\mathrm{G})=$ $112 \mathrm{MPa}$

Spring index $(C)=D / d$

Shear stress factor $\left(\mathrm{k}_{\mathrm{s}}\right)=1+(1 / 2 \mathrm{C})$

Resultant shear stress $\mathrm{G}=8 \mathrm{WDks} / \pi \mathrm{d}^{3}$

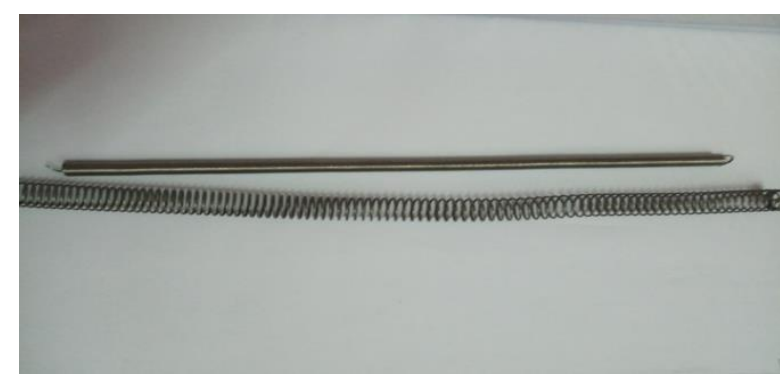

Fig 1. Springs of different mean diameters used

Deflection of spring $=8 \mathrm{WD}^{3} \mathrm{n} / \mathrm{Gd}^{4}$ The composition of spring used is specified in table 1

Table 1.composition of spring

\begin{tabular}{|c|c|}
\hline Elements & \% Composition \\
\hline $\mathrm{C}$ & $0.08-0.15$ \\
\hline $\mathrm{Mn}$ & 2.00 \\
\hline $\mathrm{Cr}$ & $16-18$ \\
\hline $\mathrm{Ni}$ & $6-8$ \\
\hline
\end{tabular}

The calculated properties of springs taken are represented in the following table 2 .

Table 2.properties of spring

\begin{tabular}{|c|c|c|c|}
\hline Spring & $\mathbf{1}$ & $\mathbf{2}$ & $\mathbf{3}$ \\
\hline No of turns & 385 & 110 & 112 \\
\hline $\begin{array}{c}\text { Mean coil } \\
\text { diameter }\end{array}$ & $0.65 \mathrm{~cm}$ & $0.65 \mathrm{~cm}$ & $1.19 \mathrm{~cm}$ \\
\hline $\begin{array}{c}\text { Wire } \\
\text { diameter }\end{array}$ & $0.58 \mathrm{~mm}$ & $0.58 \mathrm{~mm}$ & $0.87 \mathrm{~mm}$ \\
\hline $\begin{array}{c}\text { spring } \\
\text { index }\end{array}$ & 11.2 & 11.2 & 13.67 \\
\hline $\begin{array}{c}\text { Shear } \\
\text { stress } \\
\text { factor }\end{array}$ & 1.044 & 1.044 & 1.036 \\
\hline $\begin{array}{c}\text { shear stress } \\
\text { of spring }\end{array}$ & $88.56 \mathrm{~W}$ & $88.56 \mathrm{~W}$ & $47.67 \mathrm{~W}$ \\
\hline $\begin{array}{c}\text { Deflection } \\
\text { Free length }\end{array}$ & $0.066 \mathrm{~W}$ & $0.019 \mathrm{~W}$ & $0.013 \mathrm{~W}$ \\
\hline
\end{tabular}


For the design and fabrication of vibration test rig, the stiffness of springs should be determined . the spring stiffness are found experimentally and is shown in table 3.

Table 3.stiffness of spring under varying load

\begin{tabular}{|c|c|c|c|}
\hline spring & $\begin{array}{c}\text { Stiffness } \\
1\end{array}$ & $\begin{array}{c}\text { Stiffness } \\
2\end{array}$ & $\begin{array}{c}\text { Mean } \\
\text { stiffness }\end{array}$ \\
\hline $\begin{array}{c}\text { Spring } \\
1\end{array}$ & $16 \mathrm{~N} / \mathrm{m}$ & $\begin{array}{c}15.01 \\
\mathrm{~N} / \mathrm{m}\end{array}$ & $15.51 \mathrm{~N} / \mathrm{m}$ \\
\hline $\begin{array}{c}\text { Spring } \\
2\end{array}$ & 52.06 & 50.06 & $52.06 \mathrm{~N} / \mathrm{m}$ \\
\hline $\begin{array}{c}\text { Spring } \\
3\end{array}$ & 31.4 & $34 \mathrm{~N} / \mathrm{m}$ & $32.7 \mathrm{~N} / \mathrm{m}$ \\
\hline
\end{tabular}

Arduino board as shown in fig. 2 is used for feeding the commands and help us to give inputs signals to the sensors used. Also the measured parameters are then displayed in the display devices mostly computers are used to display the measured output parameters. It has $20 \mathrm{Mhz}$ resonator with $20 \mathrm{I} / \mathrm{P} \&$ $\mathrm{O} / \mathrm{P}$ pins.

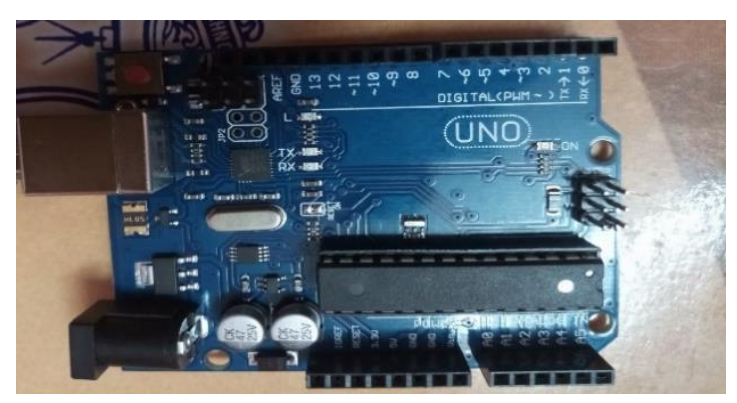

Fig.2 Arduino board

Ultrasonic sensor as shown in fig. 3 is used for measuring the deflection of the spring which is suspended by the known mass. The deflection is calculated by placing the sensor at the bottom of the rigid suspended known masses. The sensor emits ultrasonic waves such that time required for receiving the emitted signal is converted into equivalent deflection of spring.

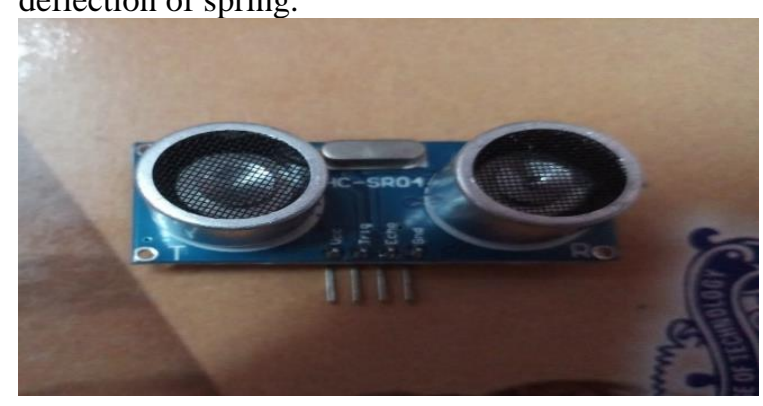

Fig.3 Ultrasonic sensor

The ADXL345 as shown in fig.4 is a small ,thin, ultralow power ,3-axis accelerometer with high resolution measures acceleration upto $+16 \mathrm{~g}$ to $-16 \mathrm{~g}$. Jumper wires are used to connect sensors with the Arduino and hence programming is done.

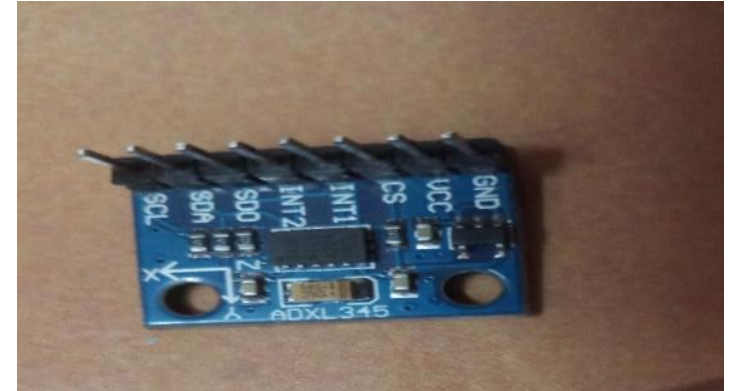

Fig .4 accelerometer sensor

The experimental setup is shown in fig 5. The displacement of the spring is measured using the steel ruler placed vertical to the base of frame. The rotating drum is used to study the variation of displacement of spring with respect to the time. It consists of two rollers, one motor is connected to one roller. A graph sheet is wound over the rollers. so that the displacement curve is traced over the graph. here one roller is stationary and one roller is in rotation. The speed of rotation can be controlled by the external loading of motor.

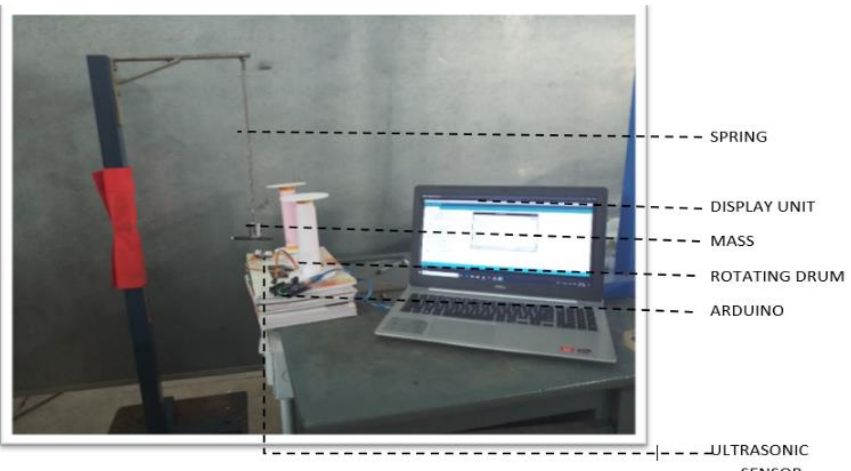

Fig .5 experimental setup

\section{RESULT}

The displacement readings obtained from the ultrasonic sensor for the three springs is been represented in the following table. These readings are achieved by transmitted and received ultrasonic waves through the preprogrammed ultrasonic sensor. Length of spring is directly proportional to the stiffness of spring. For a negligible weight the spring of shorter length remain undeflected. Table 4 represents the deflection of springs under various loading conditions.

Table 4. Deflection of springs under varying loads

\begin{tabular}{|c|c|c|c|}
\hline $\begin{array}{c}\text { Weight } \\
(\mathbf{g m})\end{array}$ & Spring 1 & Spring 2 & Spring 3 \\
\hline 50 & 0 & 0 & 1.5 \\
\hline 100 & 6 & 0 & 2.8 \\
\hline 150 & 10 & 1.3 & 4.1 \\
\hline 200 & 12 & 1.9 & 5.5 \\
\hline 250 & 15 & 2.8 & 6.5 \\
\hline 300 & 18 & 4.5 & 8 \\
\hline 350 & 21.5 & 6.3 & 9.5 \\
\hline 400 & 26.5 & 8.2 & 10.7 \\
\hline
\end{tabular}


International Journal of Research in Advent Technology, Vol.7, No.4, April 2019

E-ISSN: 2321-9637

Available online at www.ijrat.org

\begin{tabular}{|c|c|c|c|}
\hline 450 & 30.3 & 10 & 12 \\
\hline 500 & 34.5 & 11.8 & 13.5 \\
\hline
\end{tabular}

The acceleration readings shown in table 5 obtained from the accelerometer sensor for the three springs is been represented in the following table. Suspended load is directly proportional to acceleration of spring for higher weight the acceleration of spring probably high. Table 5. Acceleration readings of springs

\begin{tabular}{|c|c|c|c|}
\hline Weight (gm) & Spring 1 & Spring 2 & Spring 3 \\
\hline 50 & 9.3 & 4.506667 & 9.81 \\
\hline 100 & 10.33333 & 4.94 & 9.156 \\
\hline 150 & 9.3 & 5.824 & 8.938 \\
\hline 200 & 9.3 & 7.8 & 8.9925 \\
\hline 250 & 9.3 & 9.36 & 8.502 \\
\hline 300 & 9.521429 & 10.66 & 8.72 \\
\hline 350 & 10.26875 & 11.55556 & 8.875714 \\
\hline 400 & 10.43667 & 12.272 & 8.74725 \\
\hline 450 & 10.695 & 13.04727 & 8.72 \\
\hline 500 & 9.3 & 13.34667 & 8.829 \\
\hline
\end{tabular}

the natural frequencies in $\mathrm{Hz}$ obtained by incorporating displacement and acceleration readings to matlab program for the three springs is been represented in the following table 6 .

Table 6. natural frequency readings

\begin{tabular}{|c|c|c|c|}
\hline Weight $(\mathrm{gm})$ & Spring 1 & Spring 2 & Spring 3 \\
\hline 50 & 0.3937 & 0 & 1.186687 \\
\hline 100 & 0.321455 & 0 & 1.275178 \\
\hline 150 & 0.278388 & 0.588784 & 1.348337 \\
\hline 200 & 0.248998 & 0.509902 & 1.411217 \\
\hline 250 & 0.227303 & 0.45607 & 1.466663 \\
\hline 300 & 0.210442 & 0.416333 & 1.516451 \\
\hline 350 & 0.19685 & 0.38545 & 1.561768 \\
\hline 400 & 0.185592 & 0.360555 & 1.603452 \\
\hline 450 & 0.176068 & 0.339935 & 1.642117 \\
\hline 500 & 0.3937 & 0.32249 & 1.678229 \\
\hline
\end{tabular}

The following fig 6 . represents the displacement readings for three springs obtained from displacement sensor. From the graph the stiffer spring is spring 2 . Here the orange line represents the displacement of spring 1, the grey line represents the displacement of spring 2 and the blue line represents the displacement of spring 3 .

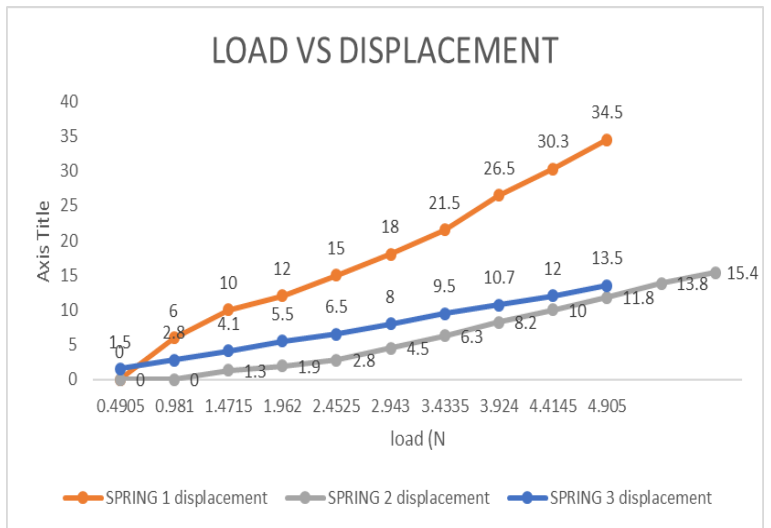

Fig 6. Comparison between load vs displacement for various springs

The following figure 7 represents the acceleration readings for three springs obtained from accelerometer sensor .spring of shorter length is initially accelerated less. Due to continuous loading the same spring is accelerated more. Here the orange line represents the displacement of spring 1 , the grey line represents the displacement of spring 2 and the blue line represents the displacement of spring 3 .

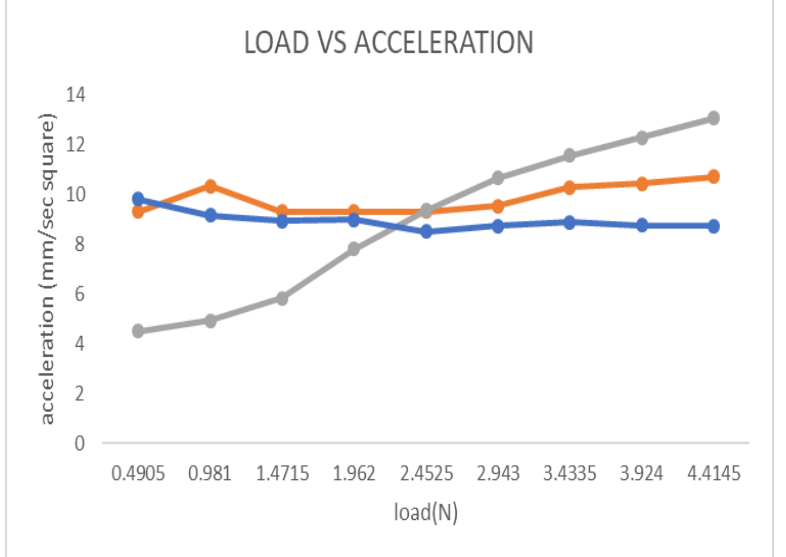

Fig 7. Comparison between load vs acceleration

The following figure 8 represents the various frequencies experienced by these three springs under different loading conditions. Frequencies are obtained from the results of MATLAB program with input parameters as displacement and acceleration. Stiffer spring possess higher natural frequency as compared to others. Here the orange line represents the displacement of spring 1, the grey line represents the displacement of spring 2 and the blue line represents the displacement of spring 3 . 
International Journal of Research in Advent Technology, Vol.7, No.4, April 2019

E-ISSN: 2321-9637

Available online at www.ijrat.org

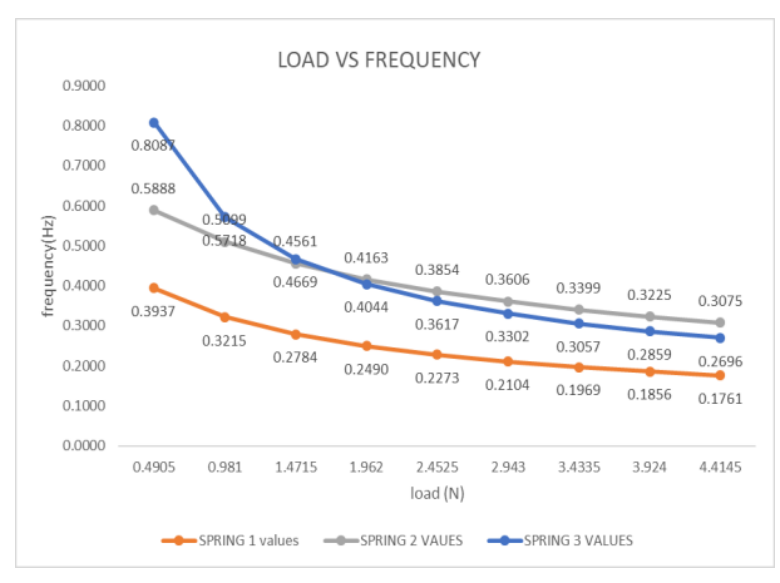

Fig 8. Comparison between load vs frequency

\section{CONCLUSION}

Hence the graphs are been plotted between acceleration, displacement and natural frequency of springs at varying load conditions were plotted using MATLAB. Readings are chosen at random for calculating percentage deviation is shown in table 6 . In order to check the design, the sensor values and theoretical values are compared. Both the values are closer. The maximum \% deviation of obtained readings is $5.45 \%$ which is very negligible. So the setup fabricated can be used as a state of art for lab purpose.

Table 6. Percentage deviation of sensor readings with actual measurement

\begin{tabular}{|c|c|c|c|}
\hline Samples & \multicolumn{3}{|c|}{ \% Deviation } \\
\hline Spring 1 & 2.5 & 0.55 & 0.75 \\
\hline Spring 2 & 5.26 & 2.22 & 3.65 \\
\hline Spring 3 & 5.45 & 2.5 & 0.934 \\
\hline
\end{tabular}

\section{REFERENCES}

[1] Liu, Hasan Easen ,2014, "Vibration control of varying spring mass damper system using voigot element", Journal of sound and vibration,421, pp 166-190.

[2] O.B. Abouletta, J. Mad1,2001 "Surface roughness prediction based on cutting parameters and tool vibrations in turning operations", Journal of Material Processing Technology,118, pp 269-277.

[3] R.Edwin Sudhagar ,A.Ananda Babu , R.Vasudevan ,P.Jeyaraj ,2015 "Vibration analysis of a tapered laminated thick composite plate with ply drop-offs", Journal Of Sound And Vibration,105,pp 145-149.

[4] Julien Meaud,2018 "Multistable two dimensional spring mass-mass lattices with tunable band gaps and wave directionality", Journal of Sound and Vibration,434, pp 44-62.

[5] Hiyoshi, Kohoku, Yokham,1995, "Vibration control of multiple mass system by estimated reaction torque", Robust and Adaptive control strategies,21, pp 367-372.

[6] Wolfgang Reinelt, 2000. "Robust control of a two mass spring system subject to its input constraints",
Journal of guidance control and dynamics, 5,pp 10571059

[7] Naveen Kuppuswamy, 2006, "Effect of physical variation on the reduced dimensional control of a mass spring damper chain system", Journal of acoustical system society of America, 34, pp 13571361.

[8] Zhi-Jia Zhang, Bin han, Feng Jin, Qian-Cheng Zhang, 2017, "Free vibration analysis of sandwich beams with honeycomb - corrugation hybrid cores", Composite structure, 3, pp 48-58.

[9] G J Liao, Xl Gong, S H Xuan, CJ Kang, LH Zong, 2011, "Development of a real time tunable stiffness and damping vibration isolator based on magnetorheological elastomer" journal of intelligence material system and structures, 23, pp 25-33.

[10] G A Yashavantha kumar, KM Satheesh kumar, 2018, "An experimental approach to free vibration analysis of smart composite beam", Material science and engineering, 314, pp 25- 33.

[11] Farley, Joseph Sebastin, "Vibration effect analysis of shock absorber with varying stiffness", Journal of sound and vibration, 99, pp 43-52

[12] K.Dupree,C.Liang,G.Hu,W.E. Dixon, 2006, "Global adaptive lyapunov-based control of a robot and massspring system undergoing an impact collision", International Journal of Robotics and Research,12,pp 672-683.

[13] Ilhwan Noh, Sangchul Won, 2007 "Control of two link robot attached to mass spring using disturbance observer", IEEE transaction on fuzzy systems, 10, pp 77-84.

[14] Keith Dupree, Chien-Hao, Liang, 2008, “Adaptive lyapunov-based control of a robot and mass-spring system undergoing an impact collision", International Journal of Robotics and Research, 8, pp 37-53.

[15] T. Mugilan, S. Santhosh and N. Sridhar,2019, "Experimental investigation of machinability and microstructure analysis on Inconel 718”, International journal of research in advent technology, Volume 7, issue 1, pp 405-409.

[16] Xing-Rong Huang, Louis Jezequl, Sebastien Besset, Lin li, 2018, "Nonlinear modal synthesis for analysing structure with a frictional interface using a generalized masing model." Journal of sound and vibration, 434, pp 166-195.

[17] Mechanical Vibrations, Graham Kelly

[18] Mechanical Vibrations, VP Singh

[19] Mechanical and Industrial Measurements, RK Jain

[20] Standards test method for measuring vibration damping properties of materials, ASTM Standards. 